\section{Malnutrition in the second year of life and psychosocial care: a case-control study in an urban area of Southeast Brazil}

\author{
Desnutrição no segundo ano de vida \\ e cuidado psicossocial: estudo caso-controle \\ em área urbana do Sudeste brasileiro
}

\author{
1 Faculdade de Medicina \\ de Botucatu, Universidade \\ Estadual Paulista, \\ Botucatu, Brasil. \\ 2 Faculdade de Saúde \\ Pública, Universidade \\ de São Paulo, \\ São Paulo, Brasil. \\ Correspondence \\ M. A. B. L. Carvalhaes \\ Departamento de \\ Enfermagem, Faculdade \\ de Medicina de \\ Botucatu, Universidade \\ Estadual Paulista. \\ Rua Petúnia 211, \\ Botucatu, SP \\ 18603-670, Brasil. \\ carvalha@fmb.unesp.br
}

\begin{abstract}
The present study aimed to identify and measure the relationship between malnutrition and psychosocial care in the second year of life. A case-control study compared 101 malnourished 12-23-month-old children (weight-for-age $<5^{\text {th }}$ percentile, WHO/NCHS) to 200 well-nourished children (weight-for-age $>25^{\text {th }}$ percentile) for exposure to various maternal behaviors related to psychosocial care. A psychosocial care score was constructed, based on the number of desirable maternal behaviors that were absent (the higher the score, the worse the quality of childcare). The association was modified by per capita family income. After adjusting for possible confounders, children from higher-income households showed no association between psychosocial care and malnutrition. For children from lower-income households, worse psychosocial care doubled the risk of malnutrition $(O R=7.26$; 95\%CI: 2.42-21.82) compared to low income alone (OR=3.08; 95\%CI: 1.28-7.42).
\end{abstract}

Child Malnutrition; Child Care; Child Nutrition
Maria Antonieta de Barros Leite Carvalhaes 1 Maria Helena D'Aquino Benício ${ }^{2}$

\section{Introduction}

Since the recognition of the importance of quality childcare as a determinant of infant nutritional status 1, considerable effort has been made by researchers and international agencies to find evidence for this relationship. One of the principal difficulties has been to construct childcare indicators that are valid and easy to measure for use in population-based studies. Food and health care indicators were proposed and tested in empirical studies, and results pointing to an association between them and malnutrition are available in the recent literature 2 . The same is not true for the psychosocial dimension of childcare, one of the largest gaps in knowledge on the care and nutritional status of small children.

Engle et al. ${ }^{3}$ proposed that mother/child (or principal caregiver/child) interaction is an indicator of the quality of psychosocial care. According to these authors, positive mother/ child interaction, characterized by such behaviors as talking regularly with the child, telling stories, embracing the child frequently, providing a safe and attractive environment, and encouraging the child's progressive independence, among other factors, can exert a protective effect on the child's nutritional status. By promoting better development, responsiveness, and progressive independence in the child, adequate psychosocial care makes children them- 
selves more capable of obtaining adequate food and health care. In addition, through a positive feedback mechanism, a healthier and more active child makes the mother feel rewarded and stimulated to invest even more in positive care practices 4,5. Another possible positive effect of psychosocial care is its favorable impact on care practices related to eating and health 6 .

Solid empirical evidence of these effects has still not been produced, although since the early 1970s researchers have already pointed to inadequate psychosocial care for malnourished children as an important factor in malnutrition causality. A pioneering study in Mexico 7 identified an association between a non-responsive mother (or person in charge of caring) and a poor environment in terms of positive social/ affective interactions and the severity of malnutrition.

Other research in both developed and developing countries has pointed to the presence of poor interaction between the mother and the malnourished child 8,9,10,11. Kerr et al. 8 investigated whether inadequate mother/child interaction could be a factor for child malnutrition in poor countries, similar to the results of some studies on the so-called "failure-tothrive" syndrome in developed countries. They compared 11 mothers of malnourished children with 11 mothers from a control group living in equally unfavorable socioeconomic conditions. Among mothers of malnourished children, symptoms such as apathy, dependence, and personal and family conflicts were more common 8.

Subsequently, studying mother/child bonding in poor families in Santiago, Chile, Valenzuela 10 found that anxious or resistant attachment was seven times more frequent in the group consisting of mothers whose children displayed chronically delayed growth, as compare to the group of mothers/children with normal growth. According to the author, disorders in mother/child attachment can explain the poor quality of mother/malnourished child interaction.

A study in the municipality of São Paulo, Brazil, reported numerous negative psychological symptoms in mothers of malnourished children: immaturity, isolation, low self-esteem, and feelings of inadequacy or inability to satisfy the child. The study identified a high prevalence of symptoms of weak mother/child attachment: unwanted pregnancy, emotional problems during gestation, sleep disorders, infant crying and intense colic, difficulties with breastfeeding, and maternal anxiety. According to the authors, these mothers showed difficulties in establishing interpersonal contacts and were depressed, unhappy, and self-focused, incapable of dealing with the child. The authors termed this situation "maternal deprivation" 7 . However, the study only included malnourished children, so the results could not be conclusive.

In a broad study on preschool children in Nepal, Gittelsohn et al. 11 detected an association between xerophtalmia and food care practices, health care, and psychosocial care. These same authors observed a strong relationship between the levels of quality in the three types of care.

Although important for reinforcing the hypothesis ascribing a determinant role to inadequate psychosocial care in child malnutrition, the above-mentioned studies were unable to present solid empirical evidence for this effect, due to such limitations as the small number of children, lack of a control group, or failure to deal appropriately with possible confounders, including socioeconomic factors (family income, maternal work, family structure), maternal characteristics (schooling and mental health), and factors related to the children themselves, such as health status and conditions at birth.

The objective of the current study was to identify and measure the association between psychosocial care and malnutrition. Specifically, we sought to identify a probable effect modification (statistical interaction) by socioeconomic status on this association, controlling for the effect of possible confounders.

\section{Methods}

\section{Design and population}

A case-control study was designed with 101 cases (malnourished children, weight-for-age below the $5^{\text {th }}$ percentile according to the World Health Organization/National Center for Health Statistics standard, or WHO/NCHS 12) and 200 controls (children of the same age with weightfor-age above the $25^{\text {th }}$ percentile for the same standard). This sample size gave the study a power of $80 \%$ to identify (with $5 \%$ statistical significance) associations with odds ratios (OR) greater than or equal to 2.5 for factors with the proportion of exposed controls ranging from 20 to $60 \%$, as proposed by Cousens et al. 13 .

Cases and controls were identified in two stages. Initially, three anthropometric surveys were performed during three consecutive nationwide vaccination campaigns. Each survey weighed children who were brought to previously defined vaccination stations, so that at 
the end of this stage all the vaccination stations in the municipality were included. A total of 1,382 children from 12 to 23 months of age were weighed, and after analyzing the data consistency (exclusion of values greater than \pm 6.0 standard deviations from the median), valid weight-for-age data were obtained for 1,288 children, corresponding to $82 \%$ of this age bracket's estimated urban population for 1997 in the city of Botucatu, São Paulo. Some 112 children were identified with weight-for-age below the $5^{\text {th }}$ percentile, and 876 children above the $25^{\text {th }}$ percentile. Among the latter, two controls were selected for each case, opting for the two children that were vaccinated immediately after the cases and who met the defined criteria. Subsequently, at the homes, after observation and an interview, the children were weighed again for confirmation of their nutritional status and group allocation in the study.

Losses were due to inability to locate some households (4 cases and 14 controls) and nonconfirmation of the initially defined nutritional status (5 cases and 10 controls). Two cases were excluded who presented a disease with an influence on growth: cerebral palsy. Thus, the actual study sample consisted of 101 cases and 200 controls.

\section{Study variables}

The dependent variable was presence or absence of malnutrition. Children were defined as malnourished (cases) who were 12 to 23 months old and had weight-for-age below the $5^{\text {th }}$ percentile in the $\mathrm{WHO} / \mathrm{NCHS}$ standard 12 and well-nourished (controls) in the same age bracket with weight-for-age above the $25^{\text {th }}$ percentile. In this age bracket, this index shows a good correlation 14 with height-for-age, recommended by the WHO 12 for diagnosis of children's nutritional status, but which was unfeasible in the present study due to technical difficulties in accurately measuring height during a mass vaccination campaign.

The target variables focused on adequacy of psychosocial care. To measure them, we prepared a list of 14 maternal behaviors indicative of positive mother/child interaction. These behaviors were selected from among the 45 behaviors in the Home Observation Measurement of the Environment (HOME) inventory created by Bradley et al. 15, designed to evaluate quality of the psychosocial environment in studies on child development and widely used in studies in both developed and developing countries. The behaviors studied here (Table 1) were those considered capable of measuring: (a) respon- siveness or sensitivity and maternal consistency in dealing with the child's needs; (b) affection, shelter, and acceptance of the child by the mother; (c) attachment or involvement with the child; (d) encouragement for autonomy and active stimulation of the child's development. Engle \& Riciutti 6 considered these characteristics essential for adequate psychosocial childcare.

An inter-observer concordance check was performed, using the kappa (k) index 16, as proposed by Landis \& Kock 17. Two interviewers observed the same 18 mother/child pairs, obtaining the following results: for 12 of the 14 maternal behaviors, concordance was good $(0.60<\mathrm{k} \leq 0.80)$ or very good $(0.80<\mathrm{k} \leq 1.0)$; for two behaviors - "caressing or kissing the child at least twice during the interview" and "not openly displaying irritation towards the child" -, concordance was fair $(0.20<\mathrm{k} \leq 0.40)$.

Factors were studied that have a known association with the child's nutritional status and that could also show an association with quality of psychosocial care, and might thus exert a confounding effect on the target association: per capita family income (in two categories, 1 st quartile and $2^{\text {nd }}+3^{r d}+4$ th quartiles); years of maternal schooling $(<4, \geq 4)$; mother's emotional state (evaluated with the SRQ-20 instrument 18 , using $<8$ symptoms as a negative result and $\geq 8$ as indicative of a possible emotional disorder); child's age (in months), sex, breastfeeding situation (currently breastfed, weaned, or never breastfed); and birth weight $(\geq 2,500 \mathrm{~g}$ and $<2,500 \mathrm{~g}$ ).

\section{Data collection}

Presence or absence of psychosocial care maternal behaviors (mother/child interaction) was detected during 30 minutes' observation of the mother/child pair in the home, in a free situation, and also while taking the child's anthropometric measurements. Two interviewers previously experienced with studies involving household data collection conducted the observation of the mother/child pairs. The other data were obtained by interviews. Data collection was supervised by one of the study authors (M.A.B.L.C.), including her presence in $20 \%$ of the interviews and confirmation of the actual conduction of $5 \%$ of the interviews, randomly drawn, using a second home visit.

\section{Analytical procedures}

Since only part of the HOME inventory 15 was used, it was not possible to adopt the authors' 
Table 1

Proportion of malnourished children (cases) and controls according to maternal behaviors indicative of psychosocial care, and the results of univariate logistic regression analyses. Botucatu, São Paulo, Brazil. 1997.

\begin{tabular}{|c|c|c|c|c|c|c|c|}
\hline \multirow[t]{2}{*}{ Observed maternal behaviors related to psychosocial care } & \multicolumn{2}{|c|}{ Cases } & \multicolumn{2}{|c|}{ Controls } & \multirow[t]{2}{*}{ Crude OR } & \multirow[t]{2}{*}{$95 \% \mathrm{Cl}$} & \multirow[t]{2}{*}{$p^{*}$} \\
\hline & $\mathrm{n}$ & $\%$ & $\mathrm{n}$ & $\%$ & & & \\
\hline \multicolumn{8}{|l|}{ Mother speaks spontaneously to child at least twice } \\
\hline Yes & 42 & 42.4 & 99 & 50.8 & 1.0 & & 0.18 \\
\hline No & 57 & 57.6 & 96 & 49.2 & 1.4 & $0.86-2.28$ & \\
\hline \multicolumn{8}{|l|}{ Mother responds verbally to vocalization by child } \\
\hline Yes & 72 & 72.7 & 155 & 79.9 & 1.0 & & 0.16 \\
\hline No & 27 & 27.3 & 39 & 20.1 & 1.5 & $0.85-2.62$ & \\
\hline \multicolumn{8}{|l|}{$\begin{array}{l}\text { Mother shows child an object or person didactically, } \\
\text { saying the name }\end{array}$} \\
\hline Yes & 13 & 13.1 & 33 & 16.9 & 1.0 & & 0.4 \\
\hline No & 86 & 86.9 & 162 & 83.1 & 1.3 & $0.67-2.69$ & \\
\hline \multicolumn{8}{|l|}{ Mother initiates verbal exchange with interviewer } \\
\hline Yes & 58 & 58.0 & 125 & 63.7 & 1.0 & & 0.30 \\
\hline No & 42 & 42.0 & 71 & 36.2 & 1.3 & $0.78-2.09$ & \\
\hline \multicolumn{8}{|l|}{ Mother praises child at least twice } \\
\hline Yes & 21 & 21.0 & 65 & 33.2 & 1.0 & & 0.03 \\
\hline No & 79 & 79.0 & 131 & 66.8 & 1.9 & $1.06-3.29$ & \\
\hline \multicolumn{8}{|l|}{ Mother transmits positive feelings when speaking about child } \\
\hline Yes & 81 & 81.0 & 169 & 86.6 & 1.0 & & 0.2 \\
\hline No & 19 & 19.0 & 26 & 13.3 & 1.5 & $0.79-2.91$ & \\
\hline \multicolumn{8}{|l|}{ Mother caresses child at least once } \\
\hline Yes & 66 & 66.6 & 140 & 71.4 & 1.0 & & 0.4 \\
\hline No & 33 & 33.3 & 56 & 28.6 & 1.3 & $0.74-2.10$ & \\
\hline \multicolumn{8}{|l|}{ Mother responds positively to praise for child } \\
\hline Yes & 82 & 82.0 & 181 & 92.3 & 1.0 & & 0.009 \\
\hline No & 18 & 18.6 & 15 & 7.7 & 2.6 & $1.27-5.52$ & \\
\hline \multicolumn{8}{|l|}{ Mother does not shout at child } \\
\hline Yes & 94 & 94.6 & 190 & 96.9 & 1.0 & & 0.23 \\
\hline No & 6 & 6.0 & 6 & 3.1 & 2.0 & $0.64-6.44$ & \\
\hline \multicolumn{8}{|l|}{ Mother does not display overt irritation towards child } \\
\hline Yes & 77 & 77.0 & 167 & 84.7 & 1.0 & & 0.1 \\
\hline No & 23 & 23.0 & 30 & 15.3 & 1.7 & $0.91-3.05$ & \\
\hline \multicolumn{8}{|l|}{ Mother does not hit child } \\
\hline Yes & 94 & 94.0 & 190 & 96.9 & 1.0 & & 0.23 \\
\hline No & 6 & 6.0 & 6 & 3.1 & 2.0 & $0.64-6.44$ & \\
\hline \multicolumn{8}{|l|}{ Mother does not verbally criticize or belittle child } \\
\hline Yes & 91 & 91.0 & 184 & 93.9 & 1.0 & & 0.4 \\
\hline No & 9 & 9.0 & 12 & 6.1 & 1.5 & $0.62-3.73$ & \\
\hline \multicolumn{8}{|l|}{ Child leaves the house at four times a week (previous week) } \\
\hline Yes & 70 & 70.0 & 155 & 78.7 & 1.0 & & 0.1 \\
\hline No & 30 & 30.0 & 42 & 21.3 & 1.6 & $0.92-2.73$ & \\
\hline \multicolumn{8}{|l|}{$\begin{array}{l}\text { Mother keeps child in her field of view or puts someone } \\
\text { in charge of this task }\end{array}$} \\
\hline Yes & 62 & 64.0 & 137 & 69.9 & 1.0 & & 0.3 \\
\hline No & 35 & 36.0 & 59 & 30.1 & 1.3 & $0.78-2.19$ & \\
\hline \multicolumn{8}{|l|}{ Psychosocial care score (number of missing behaviors) } \\
\hline 1 st tertile & 19 & 18.8 & 67 & 33.5 & 1.0 & & $0.001 * *$ \\
\hline $2^{\text {nd }}$ tertile & 44 & 43.6 & 78 & 39.0 & 1.99 & $1.06-3.73$ & \\
\hline 3rd tertile & 33 & 32.7 & 48 & 24.0 & 2.42 & $1.23-4.76$ & \\
\hline
\end{tabular}

* Wald test;

** Linear $p$ trend. 
recommended cutoff points for classifying psychosocial care as adequate or inadequate. The first step was to study the association between the presence or absence of maternal behaviors and the dependent variable, through univariate logistic regression analysis. Then a psychosocial care score was constructed, ranging from 0 to 14 , based on the number of desirable maternal behaviors that were not observed (the higher the score, the worse the quality of the psychosocial childcare). This variable was categorized in tertiles to allow comparing the effects of three levels of quality of care: more adequate, intermediate, and less adequate, identifying a potential dose-response effect. As an analytical strategy to test for the present of effect modification (statistical interaction) by per capita family income on the association between psychosocial care and malnutrition (a likely hypothesis), a new variable was constructed with four categories, consisting of the combination of per capita family income in two strata (higher, $2^{\text {nd }}+3^{r d}+4^{\text {th }}$ quartiles; lower, $1^{\text {st }}$ quartile) and the psychosocial care score, also in two strata (higher, 1st+2nd tertiles; lower, 3rd tertile) 19

Unconditional logistic regression analysis was performed, according to the procedures recommended by Hosmer \& Lemeshow 20 . Univariate and multivariate analyses were performed, adjusting the crude odds ratios for the constructed variable in order to test for statistical interaction between income, psychosocial care, and malnutrition and selected confounding factors: maternal schooling and mental health and child's sex, age, breastfeeding situation, and birth weight.

\section{Ethical aspects}

The study was approved by the Institutional Review Board of the Botucatu School of Medicine, Universidade Estadual Paulista. After extensive clarification on the study objectives and procedures, the mothers signed informed consent forms to participate.

\section{Results}

Table 1 shows the frequencies of cases and controls according to the presence or absence of each of the 14 childcare behaviors and the results of the univariate logistic regression analyses between each psychosocial care behavior and between the psychosocial care score in tertiles and malnutrition. Cases and controls differed mainly in relation to two behaviors: "moth- er praises the child at least twice", a rare event in both two groups but especially among cases; "mother responds positively to praise for the child", a quite frequent behavior in the entire study population, but less frequent among cases. Cases and controls differed in the mean psychosocial care score, worse in cases than controls $(4.8 \pm 2.74$ and $3.3 \pm 2.42$, respectively)

Categorized in tertiles, the psychosocial care score was significantly associated with the child's nutritional status (Table 1). Risk of malnutrition was greater for children in the $2^{\text {nd }}$ and 3rd tertiles of the psychosocial care score: $\mathrm{OR}=1.99$ (95\%CI: $1.06-3.73$ ) and $\mathrm{OR}=2.42$ (95\%CI: 1.23-4.76), respectively, with a significant linear trend.

By including per capita family income (a more distal determinant of nutritional status) in the analysis, the association between psychosocial care score tertiles and malnutrition was modified. Table 2 shows the results of uniand multivariate logistic regression to detect possible statistical interaction between psychosocial care, income, and malnutrition (which was in fact detected). For children from higher income households, less adequate psychosocial care (3rd tertile) did not increase the risk of malnutrition. However, for children from lower income families, the risk of malnutrition increased significantly when psychosocial care was less adequate: $\mathrm{OR}=3.08$; 95\%CI: $1.28-7.42$ for lower income children with more adequate psychosocial care and OR $=7.26$; 95\%CI: 2.42 21.82 for lower income children with less adequate psychosocial care. These results remained significant after adjusting for the potential confounding factors included in the multivariate analysis: child's age, sex, breastfeeding, and birth weight and mother's schooling and mental health.

\section{Discussion}

Some aspects pertaining to the study's validity will be considered first. As for the sample, the selection of groups based on anthropometric surveys conducted simultaneously with multivaccination campaigns proved to be an appropriate choice. This strategy allowed weighing and identifying some $82 \%$ of the children in the target age bracket residing in the urban area of Botucatu, guaranteeing greater representativeness for the cases studied than would have been obtained if they had been identified in the city's basic health care units. The selection strategy also allowed selecting the controls from the same population as the cases, thus 
Univariate and multivariate logistic regression analyses comparing per capita family income, psychosocial care score, and malnutrition. Botucatu, São Paulo, Brazil. 1997.

\begin{tabular}{|c|c|c|c|c|c|}
\hline Variable/Categories & Crude OR & $95 \% \mathrm{Cl}$ & Adjusted $O R^{\star \star \star}$ & * $95 \% \mathrm{Cl}$ & $p^{\#}$ \\
\hline Higher income*/More adequate psychosocial care score (1st or $2^{\text {nd }}$ tertile) & 1.00 & - & 1.00 & - & \\
\hline Higher income/Less adequate psychosocial care score (3rd tertile) & 0.87 & $0.41-1.86$ & 0.58 & $0.23-1.45$ & 0.246 \\
\hline Lower income ${ }^{\star \star} /$ More adequate psychosocial care score (1st or $2^{\text {nd }}$ tertile) & 3.09 & $1.48-6.44$ & 3.08 & $1.28-7.42$ & 0.012 \\
\hline Lower income/ Less adequate psychosocial care score (3rd tertile) & 6.59 & $2.67-16.26$ & 7.26 & $2.42-21.82$ & 0.000 \\
\hline
\end{tabular}

* Higher income $=$ per capita family income in the $2^{\text {nd }}, 3$ rd , or 4 th quartiles;

** Lower income $=$ per capita family income in the 1 st quartile;

$\star \star \star$ Model adjusted for child's age, sex, breastfeeding situation, and birth weight and mother's schooling and mental health status;

\# Wald test.

ensuring greater comparability between the groups.

Two measurements were taken to minimize possible classification errors for children exposed to the study factors. Both interviewers and mothers were unaware of the study's specific objectives and whether the child was a case or control, and identical questionnaires were used for cases and controls. Additional care was taken to weigh the child at the end of the observation period, thus avoiding any inference concerning nutritional status. By adopting an objective definition of the target maternal behaviors, the methodology sought to minimize possible measurement errors concerning their presence or absence. As mentioned above, there was good inter-observer concordance for 12 of the 14 behaviors investigated. However, it should be noted that no simple instruments were found for measuring psychosocial care that had been validated for use in Brazil. The choice of the HOME inventory 15 as a source for investigating maternal behaviors was due to its extensive use in scientific research, but its validity in Brazil is unknown.

One should also consider to what extent the presence or absence of maternal behaviors might have been affected by the observer's presence, which could encourage or inhibit behaviors. No indication was detected that such an influence differed between cases and controls, which supports the groups' comparability, but the observed frequencies of each of the behaviors in the mother/child interaction should not be equated with their actual occurrence in the population.

Other limitations of the study should be mentioned. The use of $a<5^{\text {th }}$ percentile cutoff for diagnosis of malnutrition may have led to false positives among cases. In fact, the WHO 12 recommends a more specific cutoff $(-2.0 \mathrm{Z}$ - score) for diagnosis of malnutrition. However, we emphasize that a less specific criterion would tend to play against the hypothesis of association between psychosocial care and malnutrition, which was detected nevertheless. One should also mention the lack of statistical power to identify risk factors with low magnitude and/or low frequency in the population, as in the case of inadequate psychosocial care. More conclusive results would require studies with higher statistical power, i.e., including more malnourished children, not present in Botucatu where the study was conducted, and the adoption of a more specific diagnostic criterion for malnutrition.

Accepting the above-mentioned limitations, the results support the study's main hypothesis, pointing to important statistical interaction between per capital family income, psychosocial care, and malnutrition. The risk of malnutrition for children from lower income households and receiving worse childcare was double that of low income alone, even after adjusting for potential confounders. Thus, adequate psychosocial care appears to act as a buffer against the negative impact of adverse socioeconomic conditions, as hypothesized by Engle et al. 3 in their theoretical model on the relationship between childcare and nutritional status and as evidenced by Ruel et al. 21 for food and health care practices in Ghana.

The most similar study to the present one was conducted in Jamaica 22 . The authors also compared cases (children with mild to moderate malnutrition) and controls to investigate the role of various maternal and family characteristics - self-esteem, depression, social support, quality of the psychosocial environment (measured by the HOME inventory ${ }^{15}$ ) and exposure to stress factors - in the determination of the child's nutritional status, conducting 
uni- and multivariate logistic regression and including socioeconomic factors in the analyses. The HOME inventory scores 15 were lower among malnourished children. Better scores were also associated with higher maternal IQ, better self-esteem, and less stress in relation to the male partner. However, after the adjusted analyses, the quality of the psychosocial environment did not remain associated with the child's nutritional status. The authors did not investigate the existence of statistical interaction between socioeconomic status, quality of psychosocial care (as indicated by mother/child interaction behaviors), and malnutrition.

Concluding, the present study detected a twofold risk of malnutrition in children from families with lower per capita income (1st quartile) when the psychosocial care score was less adequate (3rd tertile). For children of families in the higher income quartiles (2nd, $3^{\text {rd }}$, or $4^{\text {th }}$ ), the risk of malnutrition was not associated with the psychosocial care score.

These results justify further research, if possible with a longitudinal or intervention study design, in places with higher malnutrition prevalence and using a more specific criterion for diagnosing malnutrition, in order to confirm the relationship between quality of psychosocial care and nutritional status in children from low-income families. Such studies would also allow identifying the temporal relationship in this association, impossible to detect in case-control studies. Qualitative studies will also increase the understanding of how psychosocial care influences the nutritional status of low-income children in the second year of life.

\section{Resumo}

O objetivo do estudo foi identificar e medir a presença de associação entre cuidado psicossocial e desnutrição. Realizou-se estudo caso-controle incluindo 101 crianças desnutridas (peso/idade < percentil 5 do padrão NCHS/OMS), com idades entre 12 e 23 meses, que foram comparadas a 200 controles eutróficos (peso/ idade > percentil 25) em termos de sua exposição a uma série de comportamentos maternos indicadores da qualidade de seu cuidado psicossocial. Criou-se um escore de cuidado psicossocial, variando de 0 a 14, de acordo com o número de comportamentos maternos desejáveis não observados: quanto maior o escore, pior a qualidade do cuidado psicossocial. Mediante análise de regressão logística verificou-se maior risco de desnutrição para as crianças no 2 o e 3 o tercis do escore de cuidado psicossocial. Esta associação foi modificada pela renda per capita. Após ajustes para possíveis confundidores, nas crianças dos estratos superiores de renda não houve associação entre cuidado psicossocial e desnutrição. Para as crianças com nível mais baixo de renda, pior cuidado psicossocial dobrou o risco de desnutrição (OR = 7,26; IC95\%: 2,42-21,82) em relação àquele associado apenas à baixa renda $(O R=$ 3,08; IC95\%: 1,28-7,42).

Desnutrição Infantil; Cuidado da Criança; Nutrição da Criança

\section{Colaboradores}

Both authors worked on the study design, implementation, analysis, and drafting of the paper. M. A. B. L. Carvalhaes coordinated the fieldwork and wrote the final version of the article. 


\section{Referências}

1. Fundo das Nações Unidas para a Infância. Estratégia para melhorar a nutrição de crianças e mulheres nos países em desenvolvimento. Brasília: Fundo das Nações Unidas para a Infância; 1990.

2. Ruel MT, Arimond M. Measuring childcare practices: approaches, indicators, and implications for programs. Food Policy Review 2003; 6:1-81.

3. Engle L, Menon P, Haddad L. Care and nutrition: concepts and measurement. Washington DC: International Food Policy Research Institute; 1997.

4. Hopkins B, Kalverboer AF. Mother infant interaction. J Child Psychol Psychiatry 1983; 24:113-5.

5. Bentley ME, Stallings RY, Fukumoto M, Eldek JA. Maternal feeding behavior and child acceptance of food during diarrhea convalescence and health in the Central Sierra of Peru. Am J Public Health 1991; 81:43-7.

6. Engle PL, Ricciuti HN. Psychosocial aspects of care and nutrition. Food Nutr Bull 1995; 16:356-77.

7. Nóbrega FJ, Campos ALR. Distúrbios nutricionais e fraco vínculo mãe/filho. Rio de Janeiro: Revinter; 1995.

8. Kerr MAD, Bogues JL, Kerr DS. Psychosocial functioning of mothers of malnourished children. Pediatrics 1978; 62:778-84.

9. Casey PH, Bradley R, Wortham B. Social and nonsocial home environments of infants with nonorganic failure to thrive. Pediatrics 1984; 73:34853.

10. Valenzuela M. Attachment in chronically underweight young children. Child Dev 1990; 61:1984-96.

11. Gittelsohon J, Shankar AV, West KP, Faruque F, Gnalwali T, Pradhan E. Child feeding and care behaviors are associated with xerophthalmia in rural Nepal. Soc Sci Med 1998; 47:477-86.

12. World Health Organization. Physical status: the use and interpretation of anthropometry. Geneva: World Health Organization; 1995. (Technical Report Series, 854)
13. Cousens SN, Mertens TE, Kirkwood BR, Smith PG, Feachem RGA. Case-control studies of common childhood diseases: the example of diarrhoea. London: World Health Organization/MacMillan; 1995.

14. Victora CG, Gigante DP, Barros AJD, Monteiro CA, Onis M. Estimativa da prevalência de déficit de altura/idade a partir da prevalência de peso/idade em crianças brasileiras. Rev Saúde Pública 1998; 32:321-7.

15. Bradley RH, Munfrom DJ, Whiteside L, Caldwell BM, Casey PH, Kirby R, et al. A reexamination of the association between HOME scores and income. Nurs Res 1994; 43:260-6.

16. Altman DG. Practical statistics for medical research. London: Chapman \& Hall; 1996.

17. Landis JR, Koch GG. The measurement of observer agreement for categorical data. Biometrics 1977; 33:159-74.

18. Mari JJ, Williams P. A validity study of a psychiatric screening questionnaire (SRQ-20) in primary care in the city of São Paulo. Br J Psychiatry 1986; 148:23-6.

19. Agresti A. Categorical data analysis. New York: John Wiley \& Sons; 1990.

20. Hosmer DM, Lemeshow S. Applied logistic regression. New York: John Wiley \& Sons; 1989.

21. Ruel MT, Levin CE, Armar-Klemesu M, Maxwell D, Morris SS. Good care practices can mitigate the negative effects of poverty and low maternal schooling on children's nutritional status: evidence from Accra. Washington DC: International Food Research Institute; 1999.

22. Baker-Henningham H, Powell C, Walker S, Grantham-McGregor S. Mothers of undernourished Jamaican children have poorer psychosocial functioning and this is associated with stimulation provided in the home. Eur J Clin Nutr 2003; 57:786-92.

Submitted on $17 /$ Nov/2004

Final version resubmitted on 26/Sep/2005

Approved on 21/Oct/2005 